\title{
ASPECTOS GENERALES DEL SISTEMA DE PRODUCCIÓN GANADERA DOBLE PROPÓSITO EN EL MUNICIPIO DE ARAUCA [COLOMBIA]
}

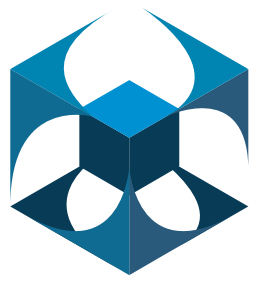

REPORTES DE I NVESTIGACIÓN

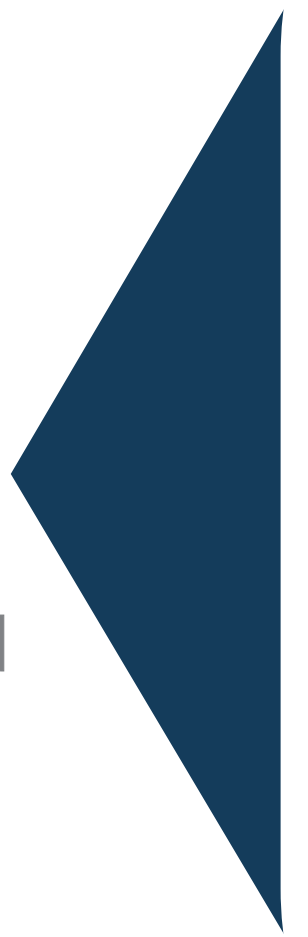

ARCESIO SALAMANCA-CARREÑO JANNET BENTEZ MOLANO RENÉ ALEJANDRO CROSBY

Universidad Cooperativa de Colombia Sede Villavicencio y Arauca
APROPIACIÓN SOCIAL DEL CONOCIMIENTO WORKING PAPERS

N. ${ }^{\circ} 1$ SEPTIEMBRE DE 2021 doi: https://doi.org/10.16925/wpri.1 


\section{ACERCA DE LOS AUTORES}

Arcesio Salamanca-Carreño, especialista en Mejoramiento Genético, profesor auxiliar de la Facultad de Medicina Veterinaria y Zootecnia, Universidad Cooperativa de Colombia, sede Villavicencio, Colombia.

Correo electrónico: arcesio.salamanca@campusucc.edu.co

CVLAC: https://scienti.minciencias.gov.co/cvlac/visualizador/generarCurriculoCv.do?cod_rh=0001022903 ORCID: https://orcid.org/0000-0002-5416-5906

Google Scholar: https://scholar.google.com/citations?hl=es\&user=EqGLQZUAAAAJ

Autor ID (Scopus): https://www.scopus.com/authid/detail.uri?authorId=56505554700

Jannet Bentez Molano, magíster en Ciencias, profesora cátedra de la Facultad de Medicina Veterinaria y Zootecnia, Universidad Cooperativa de Colombia, sede Arauca.

Correo electrónico: jannet.bentez@campusucc.edu.co

René Alejandro Crosby, especialista en Docencia Universitaria, profesor auxiliar de la Facultad de Medicina Veterinaria y Zootecnia, Universidad Cooperativa de Colombia, sede Arauca.

Correo electrónico: rene.crosby@campusucc.edu.co

\section{CÓMO CITAR ESTE DOCUMENTO}

Salamanca-Carreño A, Bentez Molano J, Crosby RA. Aspectos generales del sistema de producción ganadera doble propósito en el municipio de Arauca (Colombia) (Working papers N. ${ }^{\circ} 1$ ). Ediciones Universidad Cooperativa de Colombia, 2021. doi: https://doi.org/10.16925/wpri.1 


\section{RESUMEN}

Las explotaciones del sistema ganadero doble propósito están constituidas por animales mestizos en diferentes proporciones Bos taurus-Bos indicus; su principal característica es el ordeño con presencia del ternero. Otro aspecto para tener en cuenta es que, en la mayoría de las explotaciones no se cuenta con información y, si existe, no es analizada ni interpretada. El documento tiene como objetivo presentar información de la funcionalidad técnica y estructural del sistema doble propósito en Arauca. Los datos fueron recolectados durante el desarrollo de un proyecto de investigación; se realizó una descripción de las características generales del sistema, su estructuración, aspectos de manejo y alimentación, así como los indicadores productivos y reproductivos, expresados en producción de carne y leche de los grupos raciales. Este es el primer manuscrito que reporta información de tipo productiva de los grupos raciales existentes. Se concluye que el manejo del sistema ganadero doble propósito, aún tradicional, y su mejoramiento genético para aumentar la producción consiste en la introducción de "razas de moda", por lo que se olvida el efecto de los factores medio ambientales. La falta de registros se asocia al desconocimiento de la productividad y de la estructura, así como la funcionalidad del sistema doble propósito.

Palabras clave: animales mestizos, clima tropical, peso al destete, producción de leche, sabana inundable. 
2. El SISTEMA BOVINO DOBLE PROPÓSITO EN EL MUNICIPIO DE ARAUCA

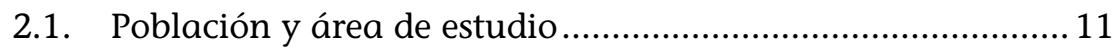

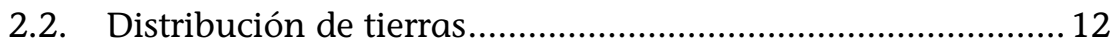

2.3. Indicadores estructurales y productivos ............................... 13

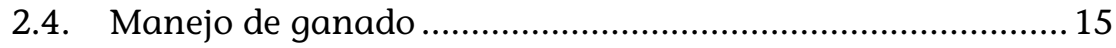

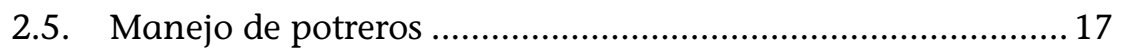

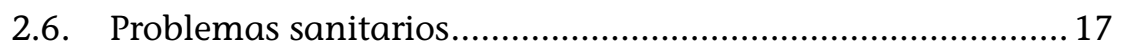

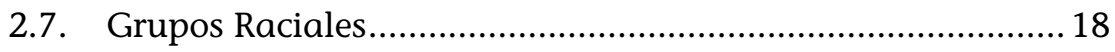

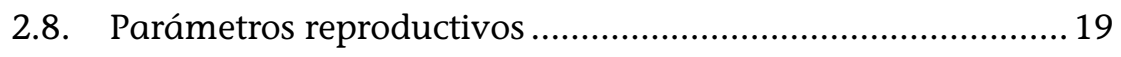

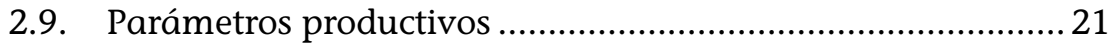

2.10. Productividad por grupo genético ........................................ 24

3. REFERENCIAS _..............................................................................27 
TABLA 1. Promedio de distribución de áreas en once fincas del sistema doble propósito en Arauca

$T A B L A$ 2. Indicadores estructurales y productivos con sus respectivos estadísticos descriptivos en once fincas del sistema doble propósito en

TABLA 3. Promedio, máxima y mínima edad al primer parto (EPP) e intervalo entre partos (IEP) en fincas del sistema doble propósito en Arauca.

TABLA 4. Promedio, máxima y mínima producción de leche y duración de la lactancia en fincas del sistema doble propósito en Arauca

TABLA 5. Promedio de duración de la lactancia y producción de leche por lactancia de tres grupos raciales en fincas del sistema doble propósito en Arauca.

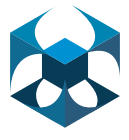


FIGURA 1. Los cruces taurus-indicus constituyen la mayor parte del Sistema Doble Propósito. Finca El Palenque.

FIGURA 2. A los grupos raciales con alta incidencia de genes lecheros se les debe medir el impacto económico que presentan en condiciones ambientales no apropiados para ellos Finca Colegio Agropecuario

FIGURA 3. La subutilización de la finca indica que la superficie disponible para el desarrollo de la actividad ganadera (116,3 ha) representa un $71 \%$ del área total, con una carga de 0,9 animales/ha. Finca Las Primaveras

FIGURA 4. La captura de información productiva es el primer requisito para tomar decisiones en el manejo de la explotación ganadera. Finca Malavares

FIGURA 5. El ternero permanece en la "vaquera" durante unos ocho días posnacimiento, aproximadamente. Finca Malavares

FIGURA 6. La mastitis de tipo subclínica es una de las enfermedades comunes en las explotaciones del Sistema Doble Propósito. Finca La Esperanza.

FIGURA 7. El uso de toros mestizos (F1 taurus-indicus) en programas de cruces planificados es una alternativa para el mejoramiento genético de la producción de leche en regiones tropicales. Finca El Palenque.

FIGURA 8. El rendimiento productivo de la finca se mide llevando controles de la producción individual de leche. Finca Trequina.

FIGURA 9. El pesaje de los terneros al destete es importante para saber las ganancias diarias de peso y la habilidad materna de la vaca. Finca Los Malavares

FIGURA 10. Vaca de medio mestizaje europeo son competentes para la producción de leche en regiones tropicales. Finca Trequina. 


\section{PRESENTACIÓN}

Cada día, en las explotaciones ganaderas, se genera gran cantidad de información productiva, técnica y económica, que es registrada, algunas veces, por los ganaderos, pero no es interpretada ni analizada para tomar decisiones sobre el mejoramiento de la finca. Por otro lado, cada explotación o finca es un sistema de producción con estructuración y funcionalidad diferentes, con parámetros e indicadores propios de cada región agroecológica que dependen, en la mayoría de los casos, de las condiciones de manejo que imponga el productor.

La producción conjunta de leche y carne en la región de sabana inundable de Arauca trasciende con el uso de animales mestizos en diferentes proporciones Bos taurus-Bos indicus, conocido como sistema de producción bovina doble propósito. Conocer en detalle el desempeño productivo de las explotaciones ganaderas es indispensable para promover las transformaciones mediante un paquete tecnológico que llegue directamente al productor.

El objetivo del presente documento es presentar información sobre la productividad de las explotaciones de dicho sistema, con base en las características técnicas y estructurales, fruto de proyecto de investigación realizado en Arauca y financiado por la Universidad Cooperativa de Colombia. El documento se constituye en el primer resultado/producto, como contribución, a la apropiación social del conocimiento, al fortalecimiento de la comunidad científica y en un mediano plazo como determinante para un programa de mejoramiento genético para el municipio.

\section{Arcesio Salamanca-Carreño \\ Jannet Bentez Molano \\ René Alejandro Crosby}




\section{CARACTERÍSTICAS GENERALES DEL SISTEMA BOVINO DOBLE PROPÓSITO}

El Sistema Bovino Doble Propósito (SDP) es considerado como un sistema tradicional de producción de la región tropical, en el cual, mediante cruzamientos de razas Bos taurus europeas especializadas o criollas con razas cebuinas Bos indicus, se obtienen simultáneamente los productos leche y carne. Por ser un sistema, se combinan diferentes factores de producción como la nutrición, el manejo genético, administración, sanidad, reproducción y manejo, los cuales contribuyen en forma asociativa a mejorar la productividad de los animales. "Su principal característica es la práctica de un ordeño manual utilizándose el ternero para estimular la bajada de la leche ('apoyo'), criándolo hasta el destete, que coincide con la terminación de la lactancia" $[1,2]$.

Otro aspecto que cimienta técnicamente al SDP es la utilización de "la leche residual que la vaca retiene durante el ordeño", que representa desde un 20 a un $25 \%$ de la producción en ganado cebú o criollo y un $15 \%$ en los animales $\mathrm{F}_{1}$ cebú-europeo. Además, el aparte del ternero produce una mejora en la eficiencia reproductiva de la vaca y obliga al ternero a consumir forraje más temprano, con lo cual el destete tiene un rumen mejor desarrollado que terneros criados a toda leche [3].

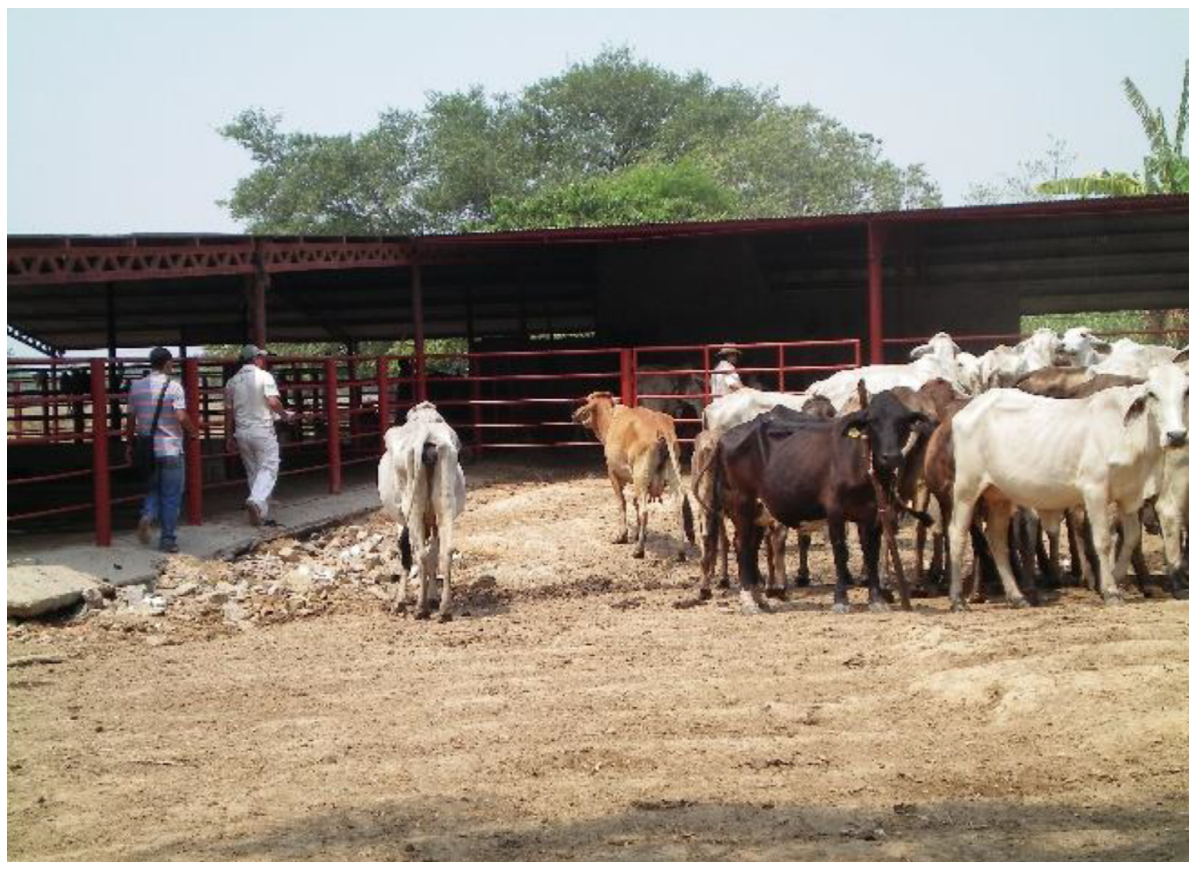

Figura 1. Los cruces taurus-indicus constituyen la mayor parte del Sistema Doble Propósito. Finca El Palenque.

Fuente: elaboración propia. 
En Colombia, el sDP "ocupa el segundo lugar con un 35\% de la actividad ganadera después de la cría, la ceba y la lechería especializada que participan con un 39\%, 20\% y $6 \%$ respectivamente; estas cifras confirman el desplazamiento de la lechería especializada hacia el doble propósito en zonas del trópico bajo colombiano" [4].

En una revisión de quince referencias bibliográficas con respecto a la productividad del SDP, se encontraron producciones de leche por lactancia que varían desde $711 \mathrm{~kg}$ en 224 días (Colombia), hasta 2989,3 kg en 302,4 días (Venezuela). De igual manera, se han alcanzado intervalos entre partos con rangos de 381,5 días (Colombia) hasta 526,5 días (Cuba). Investigaciones realizadas en Cuba, Méjico, Venezuela, Brasil y Colombia evidencian que en condiciones bioclimáticas del trópico debe conducirse el sistema al uso de animales resistentes, con capacidad de producir con eficiencia, es decir, con recursos locales y tecnologías validadas para el trópico [5].

La mayoría de las explotaciones del sDp en el trópico están constituidas por bovinos cruzados Bos taurus $x$ Bos indicus, ya que garantizan un potencial productivo para carne y leche. También existe la posibilidad de aumentar "la producción de leche a través del apareamiento de vacas cruzadas con toros mestizos que hayan sido seleccionados en regiones tropicales" [5,11,13]. El uso de animales cruzados está basado por la interacción de las razas puras (Bos taurus) con el ambiente y la baja producción de la raza Cebú (Bos índicus) [6].

De manera general, dentro de las características de manejo más predominantes que caracterizan a las explotaciones de doble propósito, podemos mencionar las siguientes [3, 5, 7]:

- Utilizan grupos raciales indefinidos como producto de cruces de ganado cebú o criollo con razas especializadas europeas (Holstein, Pardo Suizo, Normando, Jersey, entre otras).

- En algunas fincas se ordeñan tres tetas (pezones) y se deja una para el becerro y en otras fincas el productor ordeña las cuatro tetas, pero no a fondo, dejando cierta cantidad de leche para el becerro.

- Después del ordeño en la mañana, los becerros y vacas juntos van al potrero donde permanecen por un periodo de 6 a 8 horas. En la tarde (2:00 a 4:00 p.m.), los becerros se separan de sus madres y se encierran en un corral, donde pasan la noche, sin acceso a forraje, agua o a un suplemento alimenticio.

- La leche que consume el becerro de la madre es la principal fuente de alimentación durante los primeros meses de vida; en raras ocasiones se proporciona suplementación.

- El destete de los becerros se realiza entre los 7 y 9 meses de edad; de manera ocasional y según las condiciones climatológicas, el becerro permanece con la madre para alimentarse ad libitum, suspendiéndose el ordeño.

- Se utiliza mano de obra familiar.
REPORTE DE INVESTIGACIÓN

ASPECTOS GENERALES DEL SISTEMA DE PRODUCCIÓN GANADERA DOBLE

PROPÓSITO EN EL MUNICIPIO DE ARAUCA [COLOMBIA] 
REPORTE DE INVESTIGACIÓN

ASPECTOS GENERALES DEL

SISTEMA DE PRODUCCIÓN

GANADERA DOBLE

PROPÓSITO EN EL MUNICIPIO

DE ARAUCA [COLOMBIA]
- La mayoría de los productores son de bajos ingresos y combinan la explotación de bovinos con otras actividades.

- El nivel tecnológico es mínimo, lo cual se refleja en bajos índices productivos y reproductivos.

La meta de productividad en el sDp es lograr una producción de leche de $1500 \mathrm{~kg}$ en 300 días, peso al destete para machos (10 meses) de $178 \mathrm{~kg}$ (500 gr/día) y para hembras de $161 \mathrm{~kg}$ (450 g/día) y un intervalo entre partos de 365 días, lo cual indica un índice de 1 para una vaca ideal [3]. 


\section{EL SISTEMA BOVINO DOBLE PROPÓSITO EN ARAUCA}

\section{POBLACIÓN Y ÁREA DE ESTUDIO}

"El municipio de Arauca se halla localizado al oriente del departamento de Arauca en la región de sabana inundable, con una topografía plana típica de la llanura y cuenta con una extensión aproximada de 587000 hectáreas dividida en cinco corregimientos y 56 veredas". "Se estima una población bovina de 300085 animales distribuidas en 1393 predios" [8]. "La principal actividad es la cría con un tipo de explotación extensivo en la región de sabana inundable, mientras que hacia la región de vegas que se localiza más cerca al área urbana la principal actividad es el ordeño con la presencia del ternero y vacas mestizas" de composición genética taurus-indicus. Los suelos se clasifican como de textura franca, ácidos, de baja fertilidad y son considerados como de regular drenaje, cubiertos en su mayoría por gramíneas y leguminosas nativas como Paja de Agua (Hymenachme amplexicaulis), Guaratara (Axonopus purpussi), Rabo de vaca (Andropogon bicornis), Carretara (Parateria prostrata) y Lambedora (Leersia hexandra)" entre otras [5,11,13].

La posición astronómica del municipio es latitud: 07-04 N, longitud: 070-44 W, altitud: $128 \mathrm{~m}$, “con temperaturas que van desde los $35^{\circ} \mathrm{C}$ en marzo hasta los $19^{\circ} \mathrm{C}$ en enero. El régimen de lluvias es básicamente monomodal con una precipitación anual menor de $1500 \mathrm{~mm}$ que comprende los meses de abril a noviembre y con una humedad relativa del $85 \% "[9,10]$.

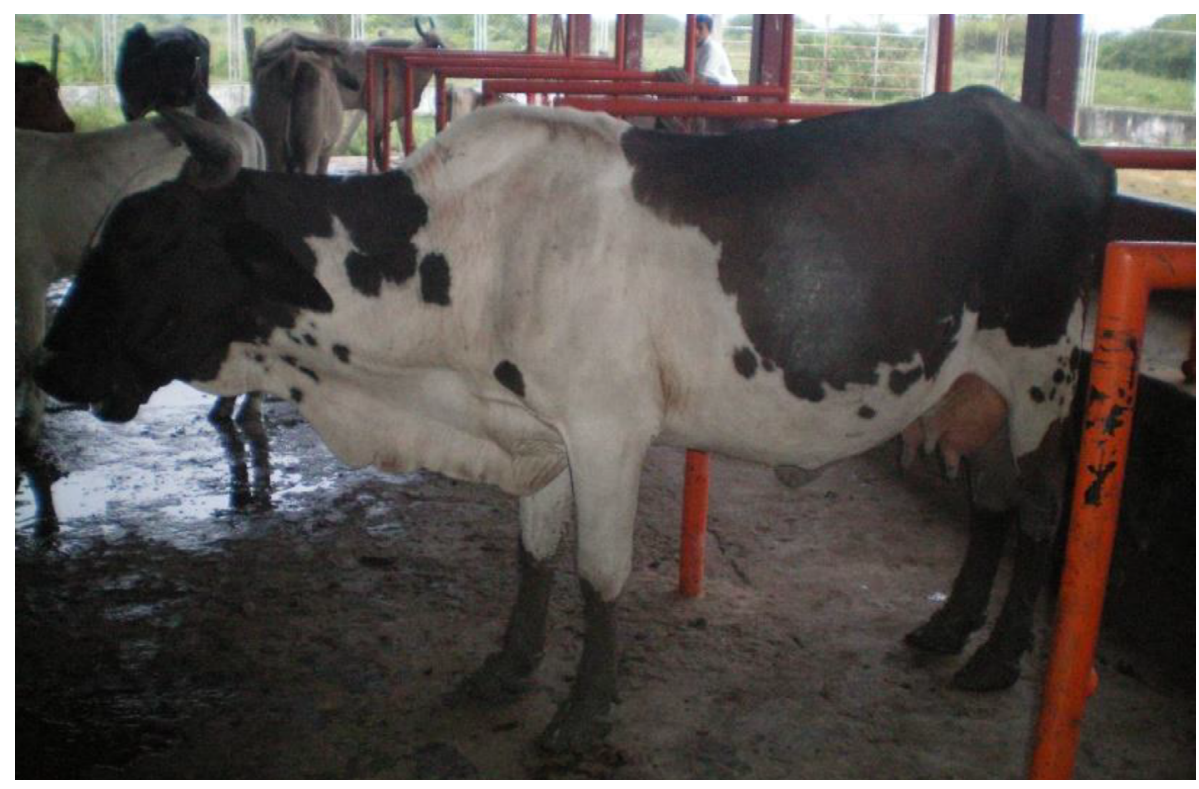

Figura 2. A los grupos raciales con alta incidencia de genes lecheros se les debe medir el impacto económico que presentan en condiciones ambientales no apropiados para ellos. Finca Colegio Agropecuario. 
REPORTE DE INVESTIGACIÓN

ASPECTOS GENERALES DEL

SISTEMA DE PRODUCCIÓN

GANADERA DOBLE

PROPÓSITO EN EL MUNICIPIO

DE ARAUCA [COLOMBIA]
El SDP en Arauca se ha venido desarrollando empíricamente con la introducción progresiva de genes lecheros de origen europeo como la raza Holstein, Pardo Suizo, Jersey y Ayrshire, entre otras, mediante el uso de toros en monta natural o inseminación artificial, pero no se ha medido el impacto negativo o positivo que se puede estar generando con la incidencia de razas europeas puras en medios ambientes no apropiados para ellas.

\section{DISTRIBUCIÓN DE TIERRAS}

En la tabla 1 se observan los valores medios de distribución de tierras según un estudio de caracterización en once explotaciones del SDP; se encontró que el promedio de área por finca es de 163,8 ha, con una superficie destinada a pastos útiles para la actividad ganadera de 116,3 ha; lo anterior representa un porcentaje alto (71\%), en relación con el total. Sin embargo, solo se evidencia una superficie de 23,1 ha de pastos mejorados (14\%) y una amplia área, 93,2 ha de pasturas naturales, es decir, más de la mitad (57\%) del área destinado al pastoreo de la ganadería bovina. Sin embargo, algunos productores muestran poca disponibilidad para el establecimiento de pastos mejorados, mientras que otros han establecido un 97,2\% del área de su explotación en pasturas mejoras (105 ha) [11].

Tabla 1. Promedio de distribución de áreas en once fincas del sistema doble propósito en Arauca

\begin{tabular}{|l|c|c|}
\hline \multicolumn{1}{|c|}{ Variable } & Valor Promedio & \% del total \\
\hline Superficie (ha) & 163,8 & \\
\hline Total en pastos (ha) & 116,3 & 71 \\
\hline Pastos mejorados (ha) & 23,1 & 4 \\
\hline Pastos naturales (ha) & 93,2 & 57 \\
\hline Bosques (ha) & 42,7 & 24 \\
\hline Silvopastoreo (ha) & 2,0 & 1 \\
\hline Uso agrícola (ha) & 2,7 & 1 \\
\hline Construcciones (ha) & 1,3 & 1 \\
\hline Otras explotaciones pecuarias (ha) & 0,9 & 1 \\
\hline Otras áreas (ha) & 1,2 & 1 \\
\hline
\end{tabular}

Fuente: [11]

Otra información importante es en relación con la distribución de bosques que, aunque su valor promedio es de $42,7 \mathrm{ha}$, la superficie para sistemas de silvopastoreo es mínima ( $2 \mathrm{ha} / \mathrm{finca}$ ), lo que representa solo un $1 \%$ de la disponibilidad total y, en algunos casos, se carece de este recurso forrajero.

"La fuente de agua en la mayoría de las fincas proviene de pozos profundos llamados 'puntillos' de donde es succionada mediante electrobombas" [11] o a través de bombas con motor a gasolina, utilizándose tanto para el consumo humano como para los animales. Otra fuente de agua son los pozos de donde se ha extraído material de relleno para la construcción de vías carreteables de acceso. Lo anterior hace que haya 
disponibilidad del recurso hídrico para riego del pasto de corte durante el verano, sin embargo, los ganaderos no consideran necesario la inversión en equipos de riego.

\section{INDICADORES ESTRUCTURALES Y PRODUCTIVOS}

El valor promedio de tamaño de las fincas (inventario) y superficie constituyen un sistema de baja a mediana productividad (139 animales y 163,8 ha), es decir, una carga de 0,9 animales/hectárea (tabla 2). El tamaño del inventario bovino en las fincas productoras oscila en un rango de 80 a 245 animales por finca mientras que la superficie comprende desde 72 a 324 ha.

Tabla 2. Indicadores estructurales y productivos con sus respectivos estadísticos descriptivos en once fincas del sistema doble propósito en el municipio de Arauca

\begin{tabular}{|l|c|c|c|c|}
\hline \multicolumn{1}{|c|}{ Variable } & Promedio & Máximo & Mínimo & CV (\%) \\
\hline Inventario bovino (n) & 139 & 245 & 80 & 41 \\
\hline Vacas horras en producción (n) & 32 & 70 & 14 & 55 \\
\hline Vacas en ordeño (n) & 22 & 70 & 10 & 80 \\
\hline $\begin{array}{l}\text { Producción de leche (kg/día/ } \\
\text { finca) }\end{array}$ & 50,5 & 175 & 18 & 88 \\
\hline $\begin{array}{l}\text { Producción de leche (kg/mes/ } \\
\text { finca) }\end{array}$ & 1515 & 7200 & 600 & 88 \\
\hline $\begin{array}{l}\text { Rendimiento en leche (kg/día/ } \\
\text { vaca) }\end{array}$ & 2,2 & 3 & 1,5 & 18 \\
\hline Vacas en producción (\%) & 48,8 & 80 & 33,3 & 28 \\
\hline Novillas (\%) & 33,5 & 53,6 & 0 & 41 \\
\hline Carga animal (vacas/ha) & 0,9 & 1,4 & 0,5 & 35 \\
\hline $\begin{array}{l}\text { Producción de leche ha/año } \\
\text { (kg/ha) }\end{array}$ & 149,3 & 255,5 & 73 & 51 \\
\hline
\end{tabular}

Fuente: [11]

Se resalta el número promedio de vacas en ordeño (22) y su elevada variación (80\%), debido, posiblemente, a una elevada cantidad de vacas horras (32) como respuesta a un deficiente manejo reproductivo, a la presencia de hembras con alta herencia indicus o al poco porcentaje de novillas de reemplazo (33,5\%). Esta característica confirma la "heterogeneidad común en la estructura y tecnología en zonas donde existen explotaciones del sistema doble propósito y se realiza un solo ordeño con vacas de cruces indefinidos" [12].

Otra variación importante es la producción de leche por finca (50,5 $\mathrm{kg} /$ día y $1515 \mathrm{~kg} / \mathrm{mes}$ ) con un $88 \%$, respectivamente. Esta amplia variación puede estar relacionada con el número de vacas en ordeño, el efecto genético de la raza; lo más trascendental es la escasa disponibilidad de forraje para la alimentación por no contar con áreas de pastos mejorados. Sin embargo, algunos ganaderos suplementan con ensilaje de forrajes no convencionales, entre los que se destaca el ensilaje de Melina (Gmelina arbórea) y Botón de Oro (Tithonia diversifolia). 
REPORTE DE INVESTIGACIÓN

ASPECTOS GENERALES DEL

SISTEMA DE PRODUCCIÓN

GANADERA DOBLE

PROPÓSITO EN EL MUNICIPIO

DE ARAUCA [COLOMBIA]
El rendimiento animal expresado como $\mathrm{kg}$ de leche/día/vaca es de 2,2 kg de leche y es un valor característico de fincas del SDP que ordeñan una sola vez al día, que amamantan a sus terneros y vacas con alto predomino de genes cebuinos. "Este rendimiento se considera aceptable si se tiene en cuenta las condiciones agroecológicas de la región de sabana inundable" $[5,11]$.

La eficiencia productiva calculada como el porcentaje de vacas en producción señala un bajo comportamiento $(48,8 \%)$ con una variación del $28 \%$. Este bajo comportamiento puede estar señalando el deficiente manejo de los factores sanidad e higiene, alimentación y reproducción, entre otros, que inciden en la productividad del hato.

El manejo reproductivo es escaso, menos de la mitad del hato $(33,5 \%)$ corresponde al porcentaje de novillas de reposición, indicador que está mostrando que el productor no descarta vacas improductivas; lo anterior demuestra que la selección de novillas de reemplazo es un aspecto que no se tiene en cuenta en el mejoramiento reproductivo del hato; sin embargo, existe una amplia variación en las fincas (41\%). El mínimo porcentaje de reposición (0\%) corresponde a una finca donde solo se mantienen las vacas lactantes, ya que las novillas son manejadas en otra explotación.

La variable producción de leche/ha/ $(149,3 \mathrm{~kg})$ es baja y se observa que es el reflejo de una ineficiencia en la productividad de la pradera. En la mayoría de los productores, el sistema de pastoreo es continuo a lo que se le suma, además, el sobrepastoreo lo que conlleva el deterioro de la pradera. Este es uno de los factores negativos para el sDP en sabana inundable.

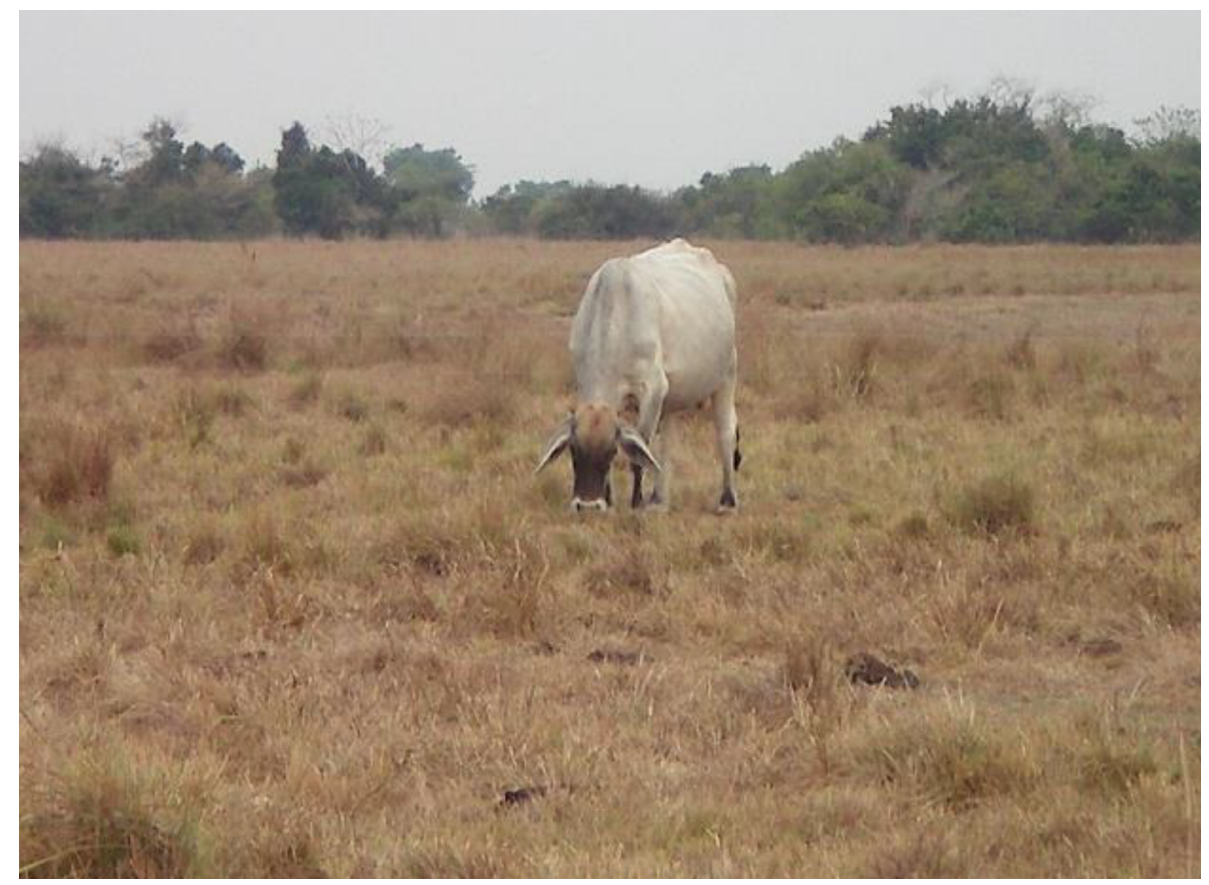

Figura 3. La subutilización de la finca indica que la superficie disponible para el desarrollo de la actividad ganadera (116,3 ha) representa un 71\% del área total, con una carga de 0,9 animales/ha. Finca Las Primaveras. 


\section{MANEJO DE GANADO}

La implementación de registros y captura de información productiva ha tomado relevancia en los ganaderos, puesto que se considera como un factor importante en la toma de decisiones en el manejo de los animales. La información que se registra en forma permanente corresponde especialmente a eventos reproductivos (partos) y sanidad (vacunas, baños contra ectoparásitos). Esta información es muy valiosa, pero, en cierto sentido, es desaprovechada por la falta de análisis e interpretación de algunos indicadores productivos.

"Con relación al manejo del ternero, este permanece habitualmente en la 'vaquera' o establo durante unos ocho días post nacimiento, aproximadamente. Posteriormente y después del ordeño es liberado con la madre al potrero donde permanece hasta las 14:00 o 16:00 horas para luego ser separado y encerrados en corral hasta el siguiente ordeño donde se utiliza para el 'apoyo' o bajada de la leche" [11]. Este es un manejo tradicional en las explotaciones y es una de las consecuencias de anestros prolongados en las vacas lactantes, lo que origina amplios intervalos entre partos, posiblemente, por un bloqueo hormonal producción-reproducción debido al efecto permanente del ternero al lado de la vaca. "En el periodo de encerramiento del ternero (permanencia en corral) no se evidencia ningún tipo de suplementación alimenticia" [11]. En excepcionales ocasiones es llevado a un potrero independiente, pero sin disponer de una buena calidad de pastura.

Es importante señalar que aún no se ha tomado razón de la práctica del amamantamiento restringido, puesto que el ganadero lo considera como una actividad que le genera más "trabajo" al encargado o mayordomo de la finca y, adicionalmente, en muchas explotaciones no se cuenta con la disponibilidad de potreros. Los productores argumentan que esa restricción conduce a un bajo peso del ternero, pero sin inferencias técnicas con respecto al fortalecimiento del rumen del ternero y a la reactivación fisiológica del ciclo reproductivo de la vaca. El descorne y curación no es muy evidente, puesto que son muy pocos los ganaderos que aplican medicamentos de tipo preventivo.

El manejo de hembras próximas al parto y de vacas horras se realiza con el resto del hato, sin embargo, algunos ganaderos disponen de potrero de parición o potero preparto. El diagnóstico del estado reproductivo de las vacas es muy insuficiente en el conjunto de las explotaciones en el sentido en que no se efectúan palpaciones rectales por parte de un técnico, mostrándose casos en los que las vacas solo tienen un periodo seco de ocho días aproximadamente, e inclusive un periodo menor, lo cual repercute en una disminución de la producción en la siguiente lactancia, consecuencia causante de un ineficiente manejo reproductivo.

"El periodo de duración de la vaca en ordeño (lactancia) lo determina la cantidad de leche producida, la condición corporal y la disponibilidad de pasto. Factores medioambientales como época de excesivo invierno (lluvias) y de excesiva sequia (verano) también están asociados al sistema de producción"; suspensión del ordeño en ciertas explotaciones, es decir, se liberan la mayoría de las "vacas debido a alta incidencia de plagas (zancudos, jejenes), condiciones de encharcamiento de los co- 
REPORTE DE INVESTIGACIÓN

ASPECTOS GENERALES DEL

SISTEMA DE PRODUCCIÓN

GANADERA DOBLE

PROPÓSITO EN EL MUNICIPIO

DE ARAUCA [COLOMBIA] rrales de manejo por no disponer de un techo", y por la escasa disponibilidad de pasturas en los potreros, entre otros. "Este fenómeno climático desequilibra la productividad de la finca y por ende el factor económico al ganadero" [11].

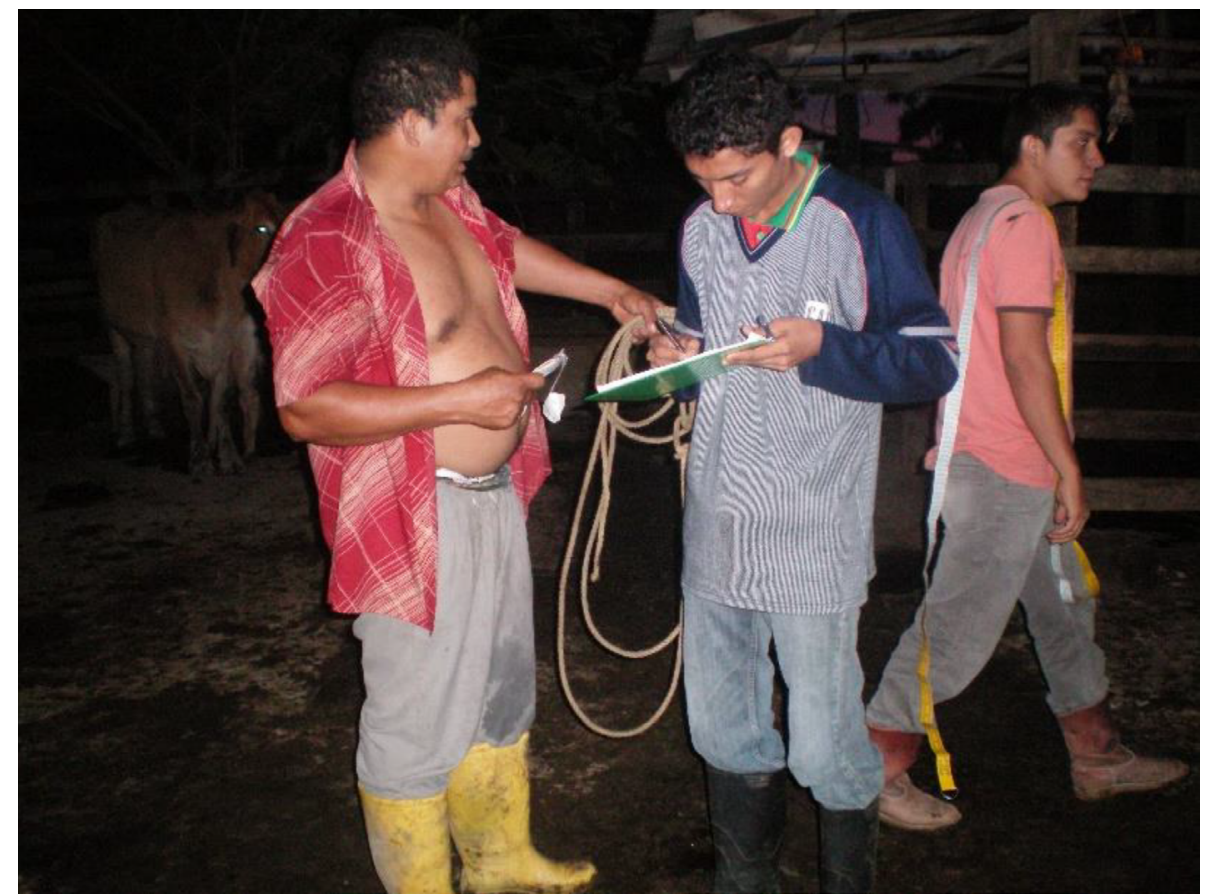

Figura 4. La captura de información productiva es el primer requisito para tomar decisiones en el manejo de la explotación ganadera. Finca Malavares.

Fuente: elaboración propia.

El sistema "reproductivo se realiza mediante monta natural en apareamiento continuo" y muy pocos utilizan de forma ocasional el servicio de inseminación artificial programada para lo cual utilizan semen de toros Bos indicus y Bos taurus. No hay programa de manejo genético, la selección y los cruces se establecen de "forma arbitraria por el propio ganadero influenciado por la raza de moda sin constituir un horizonte genético" [11]. Es así como se visualizan "mosaicos" de grupos genéticos indefinidos que pueden ser de alto valor genético, pero de inadmisible adaptación a las condiciones medioambientales.

La leche producida durante el ordeño es recolectada y medida en cantinas de aluminio o en recipientes plásticos y posteriormente es recogida por una persona llamada "crudero", quien la transporta en motocicletas y la distribuye individualmente en la ciudad; en ocasiones, es llevada a un centro de procesamiento artesanal. Durante el proceso de traslado de la leche desde la finca hasta el casco urbano pueden presentarse inestabilidades físico químicos del producto, pero actualmente se ha prestado atención por parte de las entidades de control sanitario.

"La suplementación se realiza ocasionalmente al lote de vacas en ordeño, utilizando generalmente fuentes energéticas como la melaza y regularmente, según a disponibilidad en la finca, se adiciona pasto de corte" [5, 11]. En algunas explotaciones se observa el suministro habitual de sal mineralizada. 


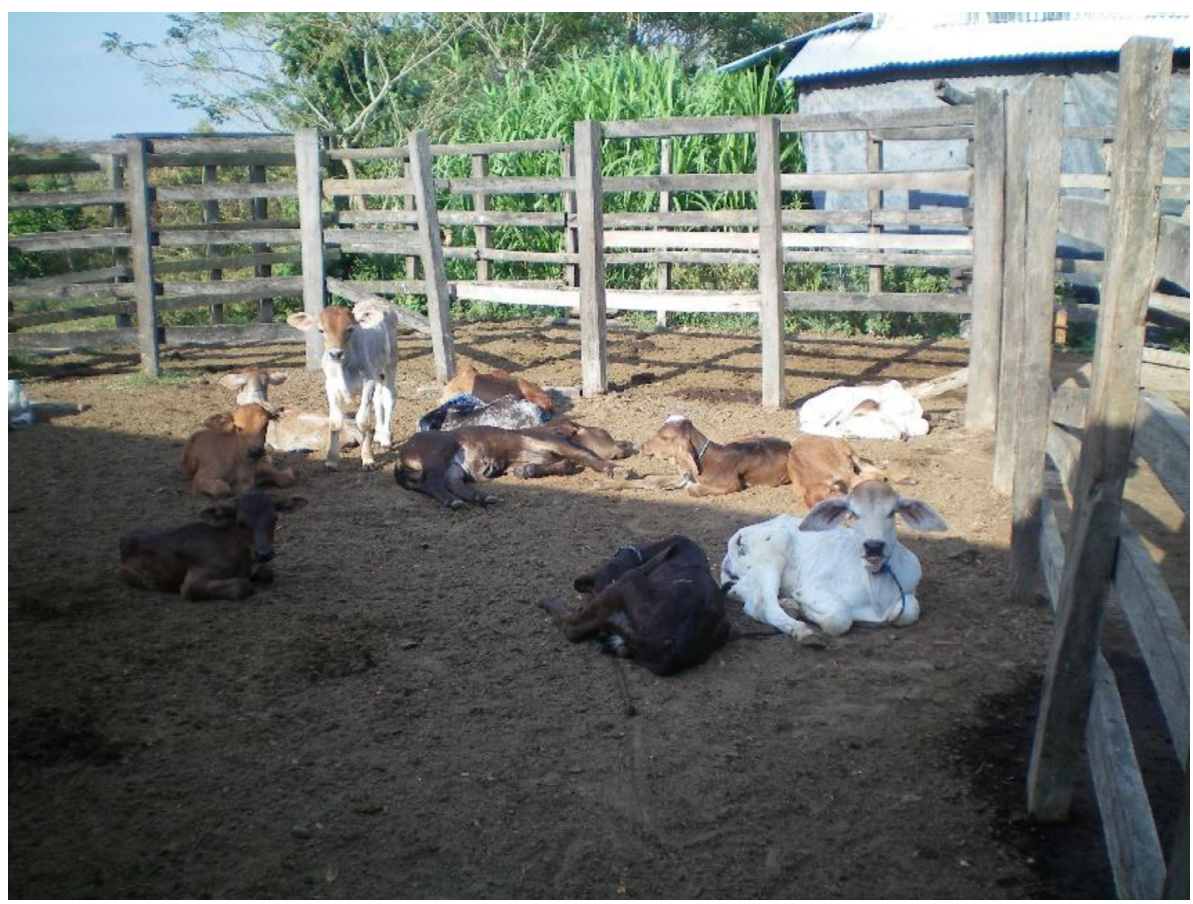

Figura 5. El ternero permanece en la "vaquera" durante unos ocho días posnacimiento, aproximadamente. Finca Malavares.

Fuente: elaboración propia.

\section{MANEJO DE POTREROS}

En relación con el manejo de potreros, en raros casos, se efectúa fertilización de mantenimiento, principalmente. No hay establecido un criterio de periodo de ocupación y de descanso, la rotación del potrero se realiza en forma flexible, es decir, mediante la observación de la disponibilidad de pasturas en el potrero, trabajo que se ejecuta en la época de invierno. Entre tanto, durante el verano el manejo consiste en el sistema de pastoreo continuo. No es usual la práctica de renovación de los potreros, lo cual ha extendido en un alto porcentaje la degradación de las praderas.

\section{PROBLEMAS SANITARIOS}

El mayor control sanitario "es la vacunación contra la Fiebre Aftosa y la Brucelosis bovinas", puesto que este es un programa de ley que está liderando la Federación Nacional de Ganaderos (Fedegan), desde 1997. La sanidad animal es un factor que debe tomar gran relevancia en el aspecto reproductivo del hato y se deduce del hecho de la compra de reproductores en otras regiones sin diagnostico sanitario que pueden estar introduciendo enfermedades de tipo reproductivo. Los problemas de cojeras son comunes en las vacas de producción (ordeño), por lo tanto, es muy frecuente durante el inicio y la finalización del periodo de lluvias, asociado principalmente al mal estado ambiental de los corrales de manejo; otro problema es la presencia de diarrea y de metritis, principalmente en animales adultos. 


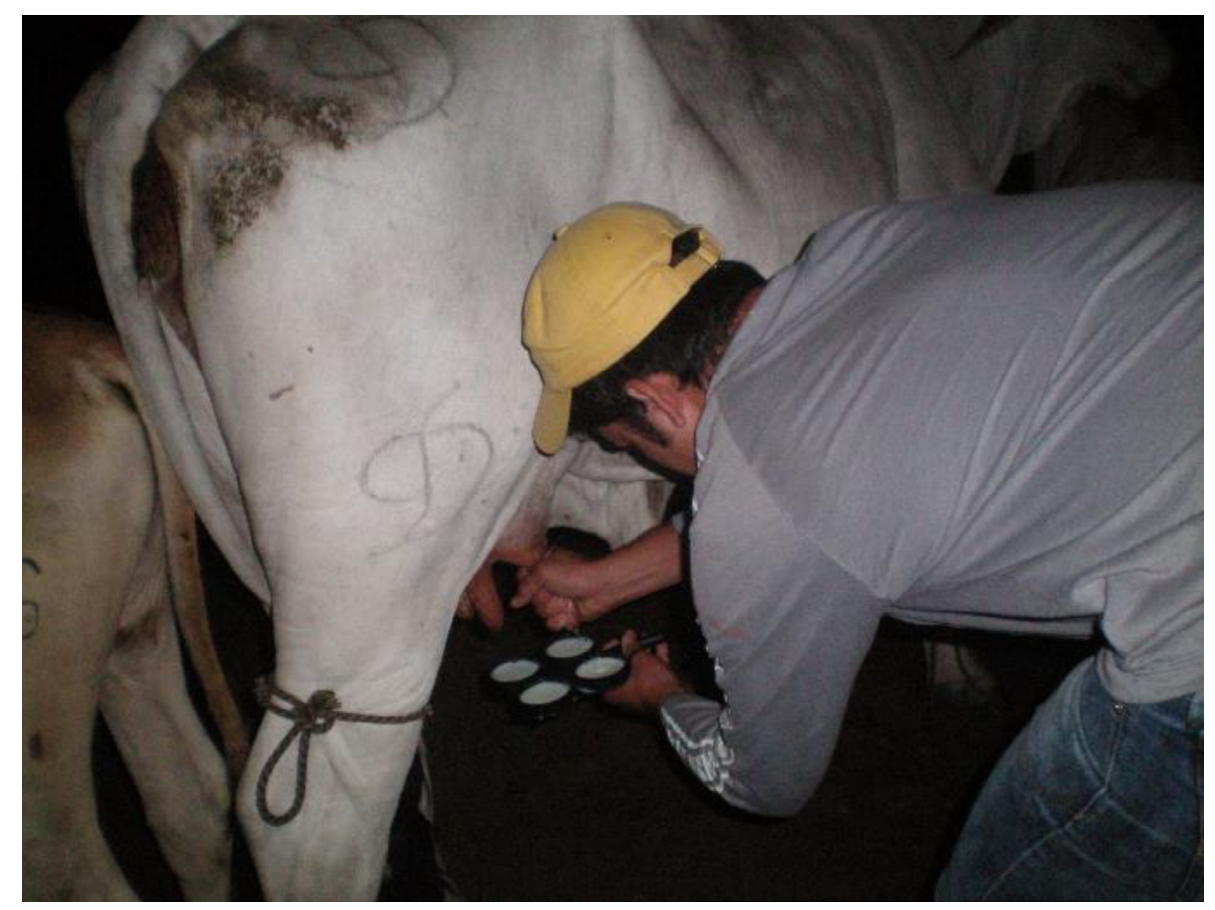

Figura 6. La mastitis de tipo subclínica es una de las enfermedades comunes en las explotaciones del Sistema Doble Propósito. Finca La Esperanza.

Fuente: elaboración propia.

La mastitis subclínica es otra enfermedad con presencia en el 45,5\% de las fincas y fue confirmado mediante la prueba de California Mastitis Test. Se encontró un 35,7\% de los animales muestreados positivos con indicios,,++++++ de mastitis subclínica y puede considerarse que una de las causas de esta enfermedad es de origen higiénico. Otras enfermedades frecuentes que afecta la productividad y que fue diagnosticada en el $63,6 \%$ de las explotaciones son las denominadas anemias causadas por hemoparásitos; un muestreo realizado al azar confirmó que un 19,6\% de animales eran positivos a anaplasma, mientras que un 2,8\% indicó presencia de anaplasma y babesia, y babesia, respectivamente. Ningún espécimen fue efectivo para Tripanosoma.

Puede considerarse que la causa de estas enfermedades es el escaso control de sus principales vectores, como son los ectoparásitos, principalmente moscas y garrapatas; lo anterior debido a que en el instante en el que se realizan los baños garrapaticidas o mosquicidas no existe una dosificación de la cantidad adecuada del ingrediente activo, además, con el "cacorro" o bomba de espalda que es oficialmente el equipo utilizado se pretende bañar a más de cincuenta animales. A las circunstancias anteriores también se les suma la presencia de animales con alto predominio de genes Taurus, no adaptado a las condiciones medioambientales.

\section{GRUPOS RACIALES}

Debido a los heterogéneos cruces que se realizan en las explotaciones del SDP se generan diferentes grupos genéticos que muestran comportamiento productivo diferente y en la mayoría se desconoce la genealogía de los 
animales. Por tal motivo, se efectuó una "clasificación de grupos raciales teniendo en cuenta la apariencia externa del animal", según lo referenciado por varios autores $[5,13,14]$. $^{-}$

Predomino indicus (bajo mestizaje europeo): animales que por su apariencia externa presentan menos del 50\% herencia Bos taurus presentando fenotipo de las razas Brahmán, Gyr, Gucera y otras cebuinas.

\pm 50:50 taurus-indicus (medio mestizaje europeo): animales que por su apariencia externa presentan un grado intermedio de herencia Bos taurus-Bos indicus.

Predominio taurus (alto mestizaje europeo): animales que por su apariencia externa presentan más del $50 \%$ de herencia Bos taurus presentando fenotipo de las razas Pardo Suizo, Normando, Jersey, Holstein, Blanco Orejinegro, Romosinuano.

\section{PARÁMETROS REPRODUCTIVOS}

El manejo reproductivo es uno de los factores de mayor importancia en la rentabilidad del hato y se deduce del hecho de que si no hay preñeces no hay partos y sin estos no existe la posibilidad de producir leche o carne.

Un parámetro importante es la edad al primer servicio de la novilla, pero la información al respecto es escasa en este sistema de producción, sin embargo, "se considera que la novilla debe incorporarse al primer servicio cuando alcance entre 70 y $75 \%$ de su peso adulto" [15].

En esta etapa se consideran algunos puntos críticos como el peso al nacer, edad al destete, "peso al destete y las ganancias diarias de peso" y sus variaciones se relacionan con la ubicación de la finca, época de nacimiento, predominio racial, criterios de manejo (de la alimentación) y gerenciales, suplementos nutricionales y programas sanitarios en el periodo pre y posdestete [16]. En la tabla 3 se exponen los promedios de edad al primer parto (EPP), intervalo entre partos (IEP) y porcentaje de preñez (PP) de fincas doble propósito localizadas en Arauca.

Tabla 3. Promedio, máxima y mínima edad al primer parto (EPP) e intervalo entre partos (IEP) en fincas del sistema doble propósito en Arauca

\begin{tabular}{|l|c|c|c|}
\hline \multicolumn{1}{|c|}{ Parámetro } & Promedio* $^{*}$ & Máximo & Mínimo \\
\hline EPP en días (EPP) & $1342(10)$ & 1775 & 1205 \\
\hline IEP en días () & $549(7)$ & 636 & 407 \\
\hline Porcentaje de preñez (\%) & $20,1(6)$ & 49 & 9,7 \\
\hline
\end{tabular}

* Los números entre paréntesis corresponde al número de fincas. Fuente: [11].

El promedio hallado para la Epp en el registro de diez fincas fue 1342 días, que representa unos 44,7 meses, con límites que van desde 1205 a 1775 días. Esta información es superior en un 14,1\% al obtenido en uno de los pocos estudios con respecto a este parámetro en SDP, cuyo valor fue de 38,9 meses y es un parámetro "que a pesar de no constituir una medida de fertilidad" afecta altamente la eficiencia productiva [17].
REPORTE DE INVESTIGACIÓN

ASPECTOS GENERALES DEL SISTEMA DE PRODUCCIÓN GANADERA DOBLE PROPÓSITO EN EL MUNICIPIO DE ARAUCA [COLOMBIA] 
REPORTE DE INVESTIGACIÓN

ASPECTOS GENERALES DEL

SISTEMA DE PRODUCCIÓN

GANADERA DOBLE

PROPÓSITO EN EL MUNICIPIO

DE ARAUCA [COLOMBIA]
La EPP es un parámetro de importancia "económica en el manejo reproductivo e inicio de la lactancia y para prolongar la vida útil de las vacas" $[15,17,18]$; es decir, entre más temprano produzca la "hembra mayor será el número de terneros y leche producidos por año de vida; además, está directamente relacionada con la edad en que se realiza el primer servicio de la novilla" [15], lo cual está condicionado por el manejo y la alimentación que se le proporcione a la novilla en el periodo de cría y levante (crecimiento) $[15,17,18]$. Se reporta que la época de parto es un factor ambiental que afecta la EPp, siendo esta menor en vacas que paren en la época seca, pero sin diferencias entre las que paren en épocas de lluvias [18, 19].

Con respecto al IEP, el promedio registrado en siete fincas fue de 549 días, que representa unos 18,3 meses, con límites que van desde 407 a 636 días (tabla 3), demostrándonos de otra forma que las vacas en el hato permanecen unos 9,3 meses en estado de vacías. Este dato es superior en un $18,5 \%$ al obtenido en otros estudios con bovinos en un sistema doble propósito, cuyo valor fue de 15,6 meses [17].

Este parámetro es considerado como uno de los mejores indicadores mediante el cual se evalúa la eficiencia reproductiva del hato; sin embargo, cuando son excesivos los IEP, es ampliamente notoria la disminución de la productividad y el progreso genético en la ganadería. Estos "periodos prolongados son consecuencia de la interacción de factores como la edad al primer parto, nutrición, grupo racial, peso al servicio, año y época de parto y el número de parto" [18, 20]; a lo anterior se suma el "limitante en regiones tropicales de encontrar hembras bovinas con anestros posparto mayores a 150 días". Se considera un intervalo entre partos ideal de "365 días para obtener parámetros productivos económicamente competitivos" [20]. Por otra parte, las vacas que paren en épocas de lluvia tienen IEP más corto sin existir diferencias entre las vacas que paren en épocas seca $[19,20]$.

En relación con el mes de parto y la duración de la lactancia, las investigaciones revelan que la exposición de vacas de alto rendimiento a "altas temperaturas ambientales durante algunos meses del año produce estrés calórico que disminuye la tasa de preñez debido a una combinación de baja detección del celo y mortalidad embrionaria" [11, 18, 20, 21]; entre tanto, el IEP es mayor entre la primera y la segunda lactancia y luego decrece hasta la última lactancia [21].

La baja condición corporal que presenta la vaca en el periodo posparto, sumado al escaso recurso forrajero, situación sanitaria y de manejo del amamantamiento son factores para prestar mayor atención en estas explotaciones ganaderas. El grupo genético que es un factor que también influye en el IEP y es afectado principalmente por los cambios ambientales, puesto que en algunas fincas hay animales con predomino taurus, mientras que en otras el predominio indicus es el más sobresaliente.

El estado de preñez de las vacas en las diferentes explotaciones se considera muy regular puesto que mediante un diagnóstico reproductivo por palpación rectal en seis fincas se encontró un 20,1\% en promedio (tabla 3). Este indicador nos visualiza en el hato la eficiencia del estado reproductivo de las vacas y nos indica, en términos porcentuales, cuántas 
vacas preñadas existen en la explotación por cada 100 vacas aptas para la reproducción. Este bajo porcentaje es el resultado del inadecuado manejo reproductivo, pobre alimentación y reducida "condición corporal de las vacas en el periodo posparto".

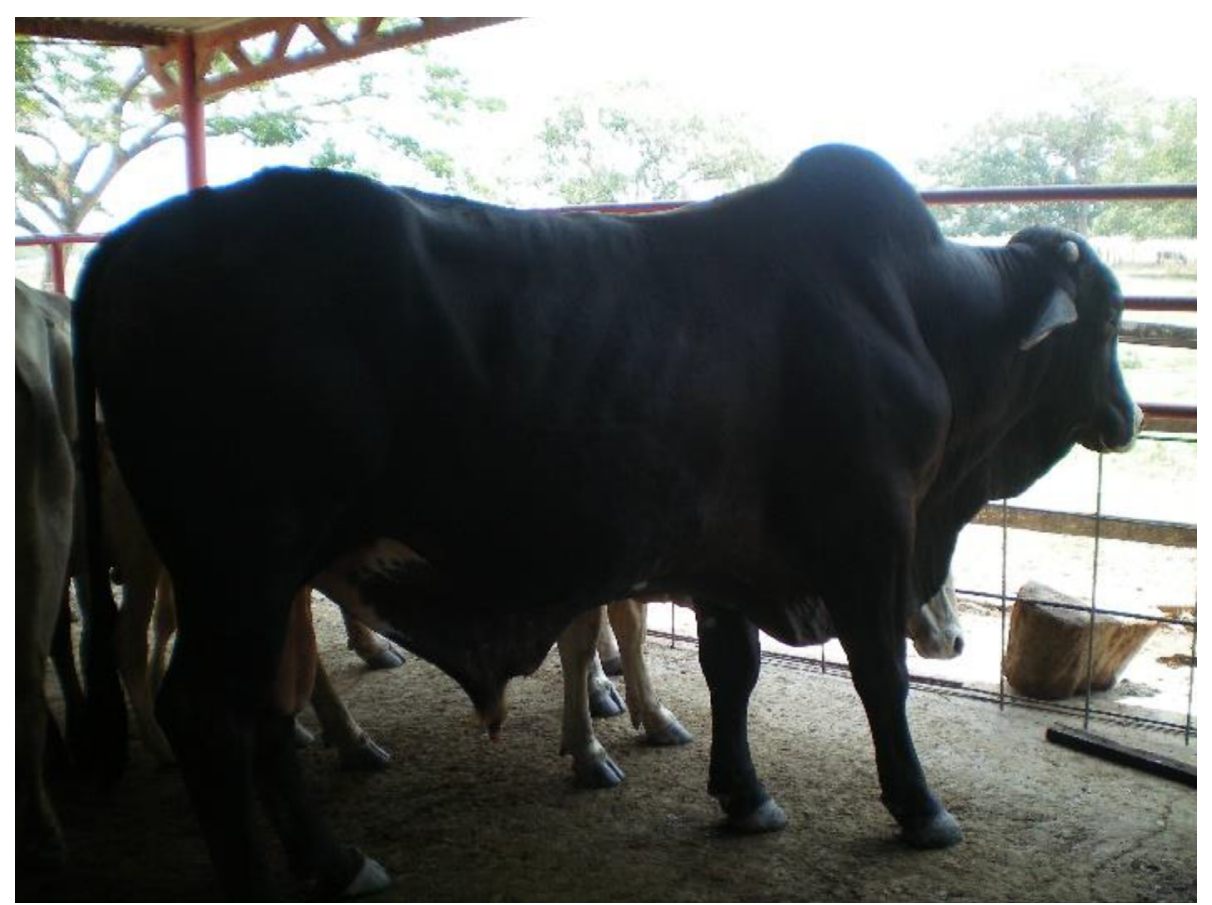

Figura 7. El uso de toros mestizos (F1 taurus-indicus) en programas de cruces planificados es una alternativa para el mejoramiento genético de la producción de leche en regiones tropicales. Finca El Palenque.

Foto: elaboración propia.

\section{PARÁMETROS PRODUCTIVOS}

"Una forma de evaluar el comportamiento productivo del sDP es mediante la medición de la producción de leche, tanto por hato (finca) como por grupo racial" [11], ya que una de las principales entradas monetarias es por la venta de leche. También se puede evaluar la producción anual de leche y peso al destete de las fincas o grupos genéticos efectuando "una relación entre la producción (leche o carne) y la reproducción (IEP)" [11], o mediante una combinación de las dos (leche + carne). Lo anterior permite visualizar la eficiencia productiva del hato llevado a términos económicos, para lo cual se destaca el riesgo de basar los análisis en tan solo la producción de leche/lactancia.

En la tabla 4 se puede analizar el comportamiento productivo en cuanto a "producción de leche y duración de la lactancia", peso al destete, edad al destete, ganancias diarias de peso, producción anual de leche y una combinación de leche más carne anual en cinco fincas del SDP en Arauca.

En términos de producción de leche/lactancia/finca, se estima un promedio de 525,6 $\mathrm{kg}$ con 250 días, de lactancia, lo que indica un rendimiento diario de $2,1 \mathrm{~kg}$, de leche. Los límites de producción van desde
REPORTE DE INVESTIGACIÓN

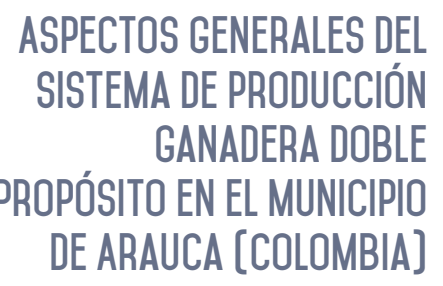


REPORTE DE INVESTIGACIÓN

ASPECTOS GENERALES DEL

SISTEMA DE PRODUCCIÓN

GANADERA DOBLE

PROPÓSITO EN EL MUNICIPIO

DE ARAUCA [COLOMBIA] los 428,8 a $626,4 \mathrm{~kg}$, lo cual demuestra "que en condiciones de sabana inundable se puede alcanzar aceptable producción de leche con animales cruzados taurus-indicus" [5, 11]. La producción promedia no es la más relevantes para el municipio, pero se acepta si tenemos en cuenta la usencia de registros, "la introducción de bovinos no adaptados y el escaso establecimiento de pastos mejorados" [11], como se mencionó anteriormente.

Estos límites de producción se les atribuyen a factores de manejo que son específicos de cada finca y lugar geográfico. En algunas fincas existen "vacas de descendencia de la raza bovina criolla Blanco Orejinegro cruzadas con reproductores indicus de la raza Brahmán y de toros cruzados Pardo Suizo y Normando por Cebú" $[1,5,11]$ o vacas de alto predominio "Bos taurus específicamente de las razas Jersey y Romosinuano o tipo Carora; entre tanto, en otras fincas se observa que la mayoría de las vacas en ordeño presentan" $[1,11]$ herencia europea intermedia, se suplementa con pasto de corte y se suministra sal mineralizada. Las características anteriores están "influyendo en la constante producción reflejado en un rendimiento diario muy inferior al promedio general, afectado por factores genéticos y ambientales que impiden la expresión de los genes productores de leche" $[1,5,11]$. Por otro lado, se registran lactancias cortas, pero de insuficiente producción diaria.

Tabla 4. Promedio, máxima y mínima producción de leche y duración de la lactancia en fincas del sistema doble propósito en Arauca

\begin{tabular}{lccc}
\hline \multicolumn{1}{c}{ Parámetro } & Promedio* $^{*}$ & Máximo & Mínimo \\
\hline Producción de leche/lactancia (kg) & $525,6(5)$ & 626,4 & 428,8 \\
Duración de la lactancia (días) & $250(5)$ & 283 & 178 \\
Rendimiento en leche (kg/día) & 2,1 & 2,2 & 1,7 \\
Peso al destete (kg) & $135,8(5)$ & 160 & 106 \\
Edad al destete (meses) & $9,7(5)$ & 10,7 & 8,9 \\
Peso del nacimiento al destete (gr/día) & $368(5)$ & 452 & 298 \\
Producción anual (leche/vaca/año) (kg) & $391,3(4)$ & 537,2 & 248,4 \\
Producción anual (PD/vaca/año) (kg) & $97,3(4)$ & 143,6 & 60,8 \\
Combinación carne + leche (kg) & $488,6(4)$ & 680,8 & 309,6 \\
\hline
\end{tabular}

* Los números entre paréntesis corresponde al número de fincas. PD: peso al destete. Fuente: [11]

Por las observaciones frecuentes a las fincas, "se evidencia que la nutrición es el principal factor que afecta la producción de leche en esas explotaciones ganaderas debido a la escasa presencia de pastos, mejorados o introducidos" [11]. "La principal fuente de alimentación son los pastos nativos, que, aunque de buena calidad, su disponibilidad de biomasa no es suficiente para suplir los requerimientos del animal. Otro limitante es el factor genético puesto que los animales de alto mestizaje europeo presentes en varias fincas reflejan la desadaptación" ambiental "exhibiendo presencia de parásitos externos y baja condición corporal" [11].

La edad promedio al destete es de 9,7 meses con un peso de 135,8 kg, lo que refleja una ganancia de $368 \mathrm{gr} /$ día (tabla 4). El máximo peso fue de $160 \mathrm{~kg}$, mientras que el mínimo fue de $106 \mathrm{~kg}$; este último se considera 
que es debido a la "influencia de genes de la raza Jersey puesto que se observaron cruces de esta raza con toros Romosinuano". "El peso al destete es un indicador de suma importancia ya que visualiza una relación positiva entre la producción de leche, el consumo de leche y la ganancia diaria de peso del ternero" [22]. Varias investigaciones han evidenciado que las "vacas de primer parto y las vacas viejas destetan becerros más livianos, mientras que los becerros que nacen en época de verano se destetan con mayor peso que los que se nacen en época de invierno" [22]. En otro estudio, encontraron "una correlación significativa del crecimiento del becerro con un periodo de seis meses de duración de la lactancia". También se han observado diferencias significativas entre la edad o el número de partos de la madre en relación con el peso al destete [23].

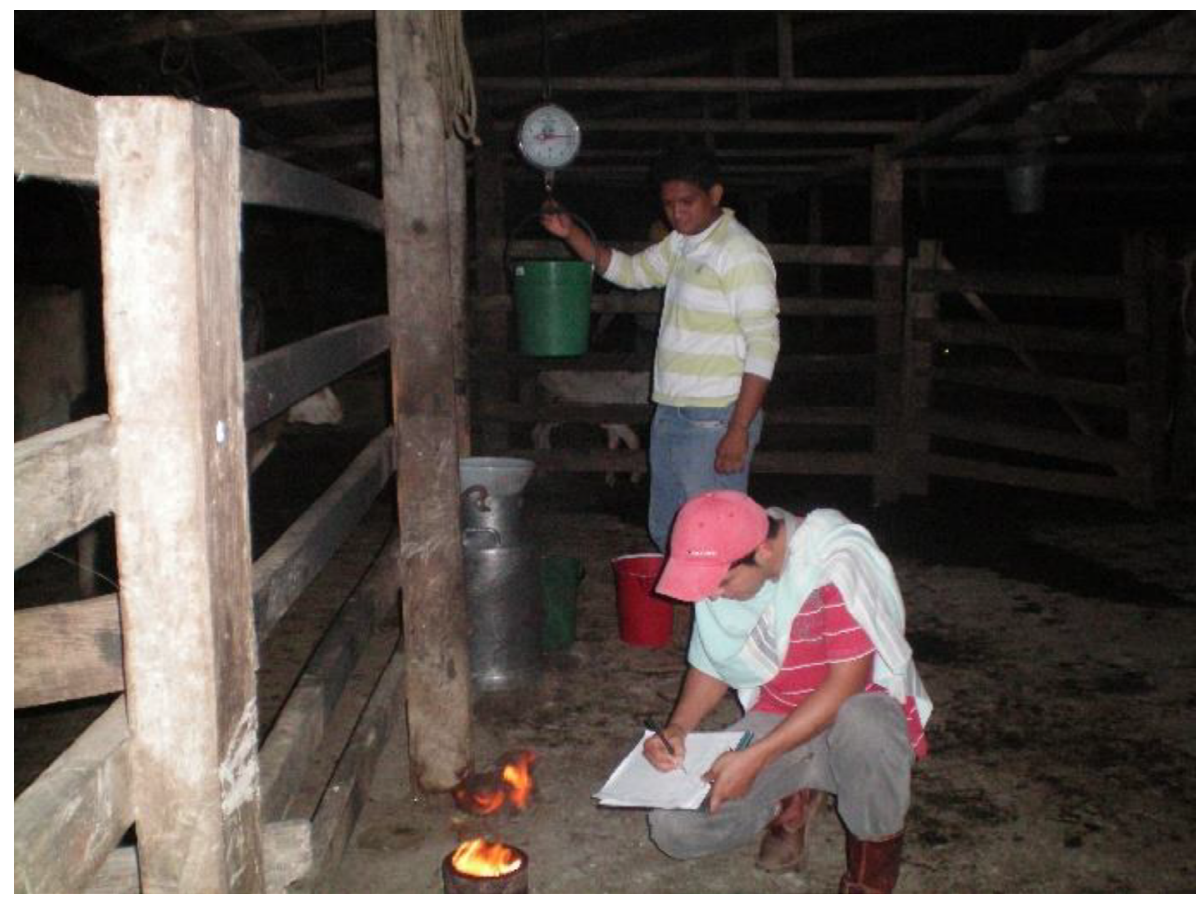

Figura 8. El rendimiento productivo de la finca se mide llevando controles de la producción individual de leche. Finca Tréquina.

Fuente: elaboración propia.

Por otra parte, "el consumo de leche en los sistemas donde se ordeña con la presencia del ternero es regulado por el tipo de amamantamiento y en forma tradicional por el ordeñador, exhibiéndose bajas ganancia de peso en los becerros, con el objeto de tener un mayor ingreso por la venta de la leche" [24, 25].

Es recomendable que los ganaderos implementen prácticas de manejo, como el amamantamiento restringido posterior al ordeño, después de tres meses de edad del becerro, lo cual conduce a que este se obligue a alimentar de forraje y no dependa solo de la leche residual y de la que aprovecha durante a permanencia con la vaca hasta el aparte. Por otro lado, con amamantamiento restringido se puede obtener mayor cantidad de leche vendible y la vaca retorna a un próximo celo en menores días posparto.
REPORTE DE INVESTIGACIÓN

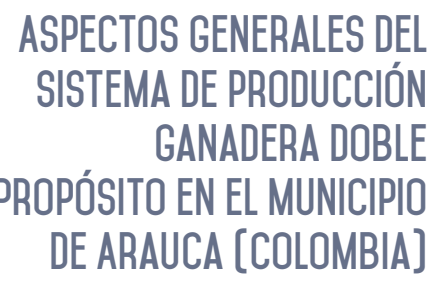




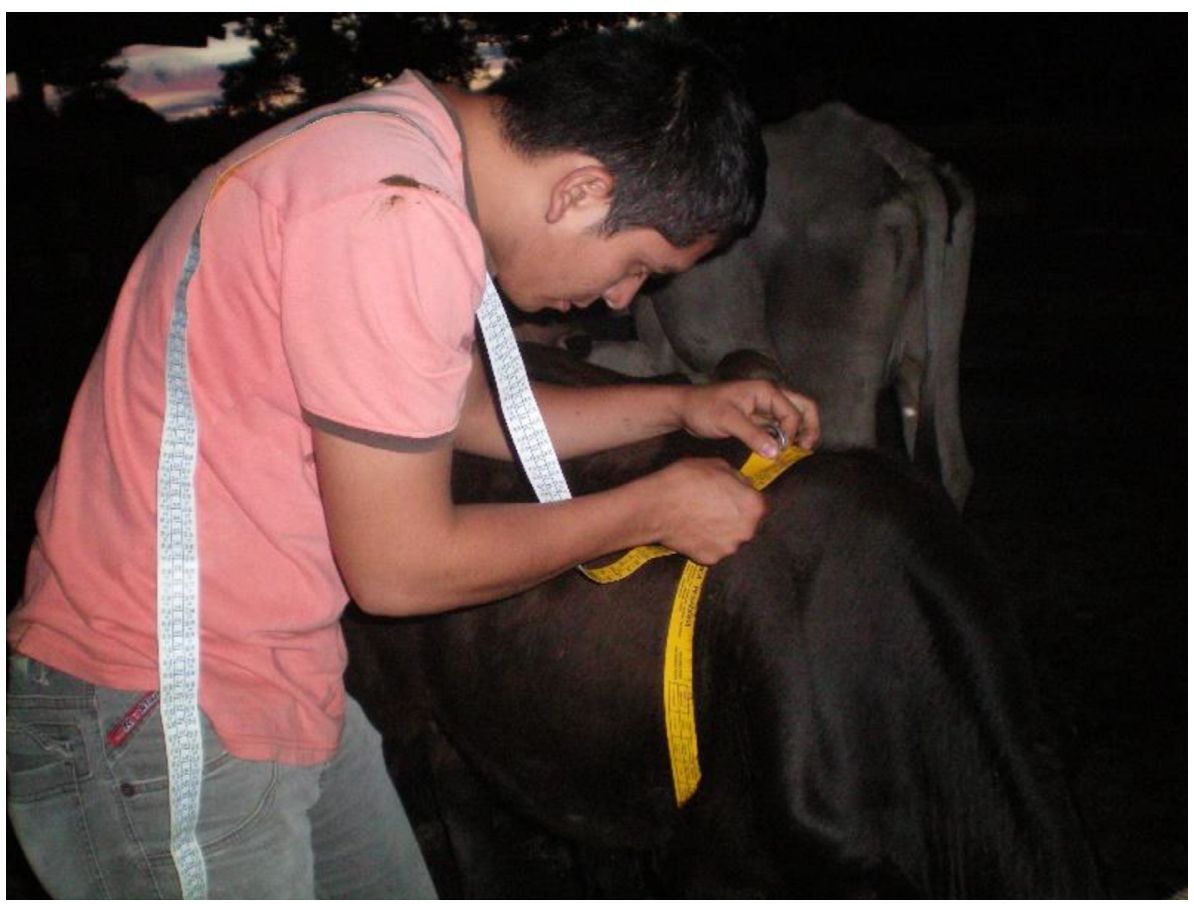

Figura 9. El pesaje de los terneros al destete es importante para saber las ganancias diarias de peso y la habilidad materna de la vaca. Finca Los Malavares.

Fuente: elaboración propia.

En los sDp localizados en Arauca, la producción anual de leche es baja con promedios de 391,3 kg, mientras que la producción anual de carne tan solo alcanza 97,3 kg/año respectivamente (tabla 4). Entre tanto, la combinación leche más carne $(488,6 \mathrm{~kg})$ está muy cerca de la producción por lactancia $(525,6 \mathrm{~kg})$, con tan solo un $7 \%$ de diferencia.

\section{PRODUCTIVIDAD POR GRUPO GENÉTICO}

En la tabla 5 se muestra la producción de leche, duración de la lactancia y parámetros reproductivos (EPP, IEP) de los tres grupos genéticos distribuidos en las fincas donde se llevan registros productivos. De la medición de 96 lactancias terminadas, se obtuvo un promedio de $517,8 \mathrm{~kg}$, de leche producidos en 232 días, lo que significa un rendimiento diario de $2,2 \mathrm{~kg}$.

Tabla 5. Promedio de duración de la lactancia y producción de leche por lactancia de tres grupos raciales en fincas del sistema doble propósito en Arauca

\begin{tabular}{|l|c|c|c|c|c|c|}
\hline \multicolumn{1}{|c|}{ Grupo genético } & $\mathbf{n}$ & $\begin{array}{c}\text { Días } \\
\text { lactancia }\end{array}$ & $\begin{array}{c}\mathbf{k g} \\
\text { lactancia }\end{array}$ & $\begin{array}{c}\mathbf{k g} / \\
\text { día }\end{array}$ & $\begin{array}{c}\text { epp } \\
\text { (días) }\end{array}$ & $\begin{array}{c}\text { iep } \\
\text { (días) }\end{array}$ \\
\hline Bajo mestizaje europeo & 57 & 254 & 483,1 & 1,9 & 846 & 628 \\
\hline $\begin{array}{l}\text { Medio mestizaje } \\
\text { europeo }\end{array}$ & 35 & 283 & 651,6 & 2,3 & 1300 & 593 \\
\hline Alto mestizaje europeo & 4 & 160 & 418,8 & 2,6 & 1143 & 562 \\
\hline Promedio general & & 232 & 517,8 & 2,2 & 1096 & 594 \\
\hline
\end{tabular}

n: número de lactancias; EPP: edad al primer parto; IEP: intervalo entre partos. Fuente: [11] 
El mejor comportamiento en producción de leche lo expresaron los animales de medio mestizaje europeo con 651,6 kg de leche/lactancia. En Arauca se ha manifestado mayor producción de leche en los cruces con predominio taurus $(1620 \mathrm{~kg})$, pero no se hallaron diferencias con respecto a las vacas de predominio indicus y 50:50 taurus-indicus [5]. También es evidente las producciones similares entre los grupos de bajo y alto mestizaje europeo, pero en el segundo es mayor el rendimiento diario, debido a sus cortas lactancias y posiblemente a la insuficiente información sobre la cantidad de lactancias medidas.

"Sin embargo, es indiscutible que el genotipo en donde interviene el cruce con Bos taurus y especialmente con la raza Holstein, la producción de leche es por lo general mayor que la de vacas cruzadas con Cebú x Pardo suizo y Cebú" [26]. Aunque las razas importadas Bos taurus tienen "alto potencial genético para la producción de leche", el estrés calórico provocado por el medio ambiente tropical afecta su productividad y sobrevivencia.

Entre tanto, el promedio de edad al primer parto (EPP) y de intervalo entre partos (IEP) para los tres grupos raciales fue de 1096 días y 594 días, respectivamente, lo cual indica que las vacas están pariendo a una edad de 36,5 meses y que los partos se suceden cada 19,8 meses. La Epp es aceptable para las condiciones de sabana inundable, pero la ineficiencia reproductiva se ve influenciada negativamente en los IEP. La mayor EPP se observó en el medio mestizaje europeo (1300 días), entre tanto, el mayor IEP fue para el bajo mestizaje europeo (628 días).

Los parámetros anteriores son superiores a los hallados en otro trabajo en el cual la menor epp fue para los animales 50:50 taurus-indicus (1182 días) y el mayor IEP (543,1 días) para los de predominio taurus, existiendo alta diferencia para el primero y no hallando diferencia para el segundo en relación con los demás grupos estudiados [5].

"Las condiciones climáticas influyen sobre la producción de leche en forma directa alterando el metabolismo del animal por las altas temperaturas, e indirectamente determinando la estacionalidad de la producción de forraje. Otros factores que influyen es la edad de la vaca, la madurez fisiológica del animal y el número de lactancia, encontrándose que vacas de cuatro lactancias son superiores en 10, 16 y $30 \%$ comparada con las de tres, dos y una lactancia respectivamente" [27]. Igualmente, la producción de leche se ve afectada por el amamantamiento y la interacción permanente de la vaca con el becerro.

"La época de parto, y año de parto también afecta significativamente la longitud de lactancia y existe una relación lineal entre el rendimiento de leche por lactancia y la duración" de esta [23]. Las investigaciones realizadas en SDP "midiendo las influencias ambientales como época y año han evidenciado que las vacas que paren al inicio de lluvias producen mayor rendimiento de leche por lactancia y el mejor promedio diario" $[14,19,23]$; estas evidencias comprueban que los efectos ambientales pueden disminuirse con una óptima alimentación y un buen manejo.

En conclusión, el manejo del sistema ganadero doble propósito en Arauca es tradicional; el mejoramiento de la producción se da con introducción de "razas de moda", por lo tanto, se olvida el efecto de los facto-
REPORTE DE INVESTIGACIÓN

ASPECTOS GENERALES DEL SISTEMA DE PRODUCCIÓN GANADERA DOBLE PROPÓSITO EN EL MUNICIPIO DE ARAUCA [COLOMBIA] 
REPORTE DE INVESTIGACIÓN

ASPECTOS GENERALES DEL SISTEMA DE PRODUCCIÓN GANADERA DOBLE PROPÓSITO EN EL MUNICIPIO DE ARAUCA [COLOMBIA] res medio ambientales. Por último, la ausencia de un sistema de registros lleva a que se desconozcan los parámetros y los indicadores de la funcionalidad y la estructuración de las explotaciones ganaderas del sistema doble propósito.

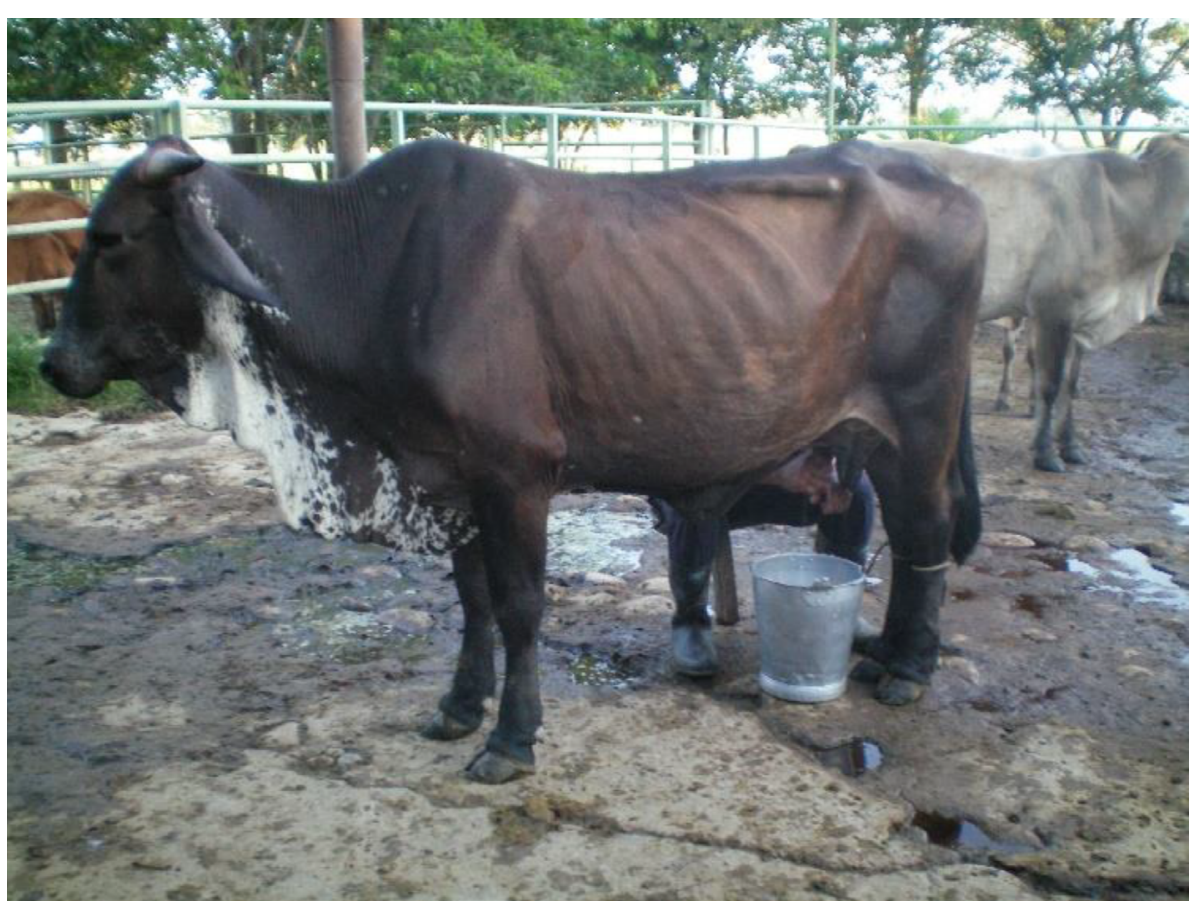

Figura 10. Vaca de medio mestizaje europeo son competentes para la producción de leche en regiones tropicales. Finca Tréquina.

Fuente: elaboración propia. 


\section{REFERENCIAS}

[1] Salamanca CA, Bentez MJ. Producción de leche de vacas mestizas del Sistema Doble Propósito en el municipio de Arauca. Redvet. Revista Electrónica de Veterinaria. 2012; 13(7): 1-16.

[2] Arce RC, Aranda EM, Osorio MM, González GR, Díaz RP, Hinojosa JA. Evaluación de parámetros productivos y reproductivos en un hato de doble propósito en Tabasco, México. Rev Mex Cienc Pecu. 2017; 8(1): 83-91.

[3] Tatis ZRE, Botero ALM. Génesis y consolidación del sistema vacuno en doble Propósito. Asodoble. Bogotá: Produmedios; 2005.

[4] Federación Nacional de Ganaderos (Fedegan). Inventario ganadero. Explotaciones ganaderas. [Online]; 2020 [citado 2020 ago 17]. Disponible en https://www.fedegan.org.co/estadisticas/inventario-ganadero

[5] Salamanca CA. Productividad de un sistema de doble propósito en sabana inundable del municipio de Arauca. En Primer Congreso Internacional Desarrollo y Producción sostenible, versión Sabanas Inundables y I Simposio Recurso Genético del Trópico Húmedo; 2008; Arauca, 29 al 31 de octubre, pp. 50-68.

[6] López OR, García CR, García Jg, Ramírez VR. Producción de leche de vacas con diferente porcentaje de genes Bos taurus en el trópico mexicano. Téc Pecu Méx. 2009; 47(4): 435-448.

[7] Osorio-Arce M. El sistema de producción bovina de doble propósito en el trópico. "La Rejeguería". Manual de producción bovina de doble propósito (Carne y Leche) en el trópico. "La Rejeguería". 1996; $1: 1-9$.

[8] Instituto Colombiano Agropecuario (ICA). Censo Pecuario [en línea]. 2019. Disponible en https://bit.ly/3kWJ5gX

[9] Instituto de Hidrología, Meteorología y Estudios Ambientales (IDEAM). Información Aeronáutica. Climatología. Precipitación media mensual y número de días [en línea]. 2000 [citado 2018 junio 2]. Disponible en http://bart.ideam.gov.co/cliciu/arauca/precipitacion.htm

[10] Arauca. Valores climatológicos normales. Clima: Arauca, Colombia [en línea]. 2021 [citado 2021 marzo 3]. Disponible en http://es.allmetsat.com/clima/venezuela.php?code=80099

[11] Salamanca CA, Bentez MJ, Crosby GRA. Caracterización productiva y reproductiva en explotaciones del Sistema Bovino en Doble Propósito en el municipio de Arauca, departamento de Arauca. Proyecto de investigación. Arauca: Universidad Cooperativa de Colombia, Arauca. Facultad de Medicina Veterinaria y Zootecnia; 2011 a.

[12] Camargo M, Colmenares O. Caracterización de sistemas de bovinos doble propósito en Veguita- Corozal y Sabana seca, municipio Guanarito, Estado Portuguesa. Rev. Unellez. Cienc. Tecn. 2009; 27: 1-8. 
REPORTE DE INVESTIGACIÓN

ASPECTOS GENERALES DEL

SISTEMA DE PRODUCCIÓN

GANADERA DOBLE

PROPÓSITO EN EL MUNICIPIO

DE ARAUCA [COLOMBIA]
[13] Vaccaro L. Caracterización de 18 rebaños venezolanos de doble propósito. En XII Reunión Latinoamericana de Producción Animal. Santiago de Chile: ALpa; 1993.

[14] Sheen RS, Riesco DA. Factores que afectan la producción de leche en vacas de doble propósito en trópico húmedo (Pucallpa). Rev Inv Vet Perú. 2002; 13(1): 25-31.

[15] González-Stagnaro C, Madrid-Bury N, Goicochea-Laque J, González-Villalobos D, Rodríguez-Urbina MA. Primer Servicio en novillas de Doble Propósito. Revista Cientif. FCV- LUz. 2007; 17(1): 39-46.

[16] Madrid-Bury N, González-Stagnaro C, Goicochea LJ, González-Villalobos D, Rodríguez-Urbina MA. Peso al nacimiento en hembras bovinas doble propósito [en línea]. Rev. Fac. Agron. 2007; 24(4). Disponible en http://ve.scielo.org/scielo.php?script=sci_arttext\&pi $\mathrm{d}=\mathrm{S} 0378-78182007000400006$

[17 Vergara GO, Botero AL, Martínez BC. Factores que afectan la edad al primer parto y primer intervalo de partos en vacas del sistema doble propósito. Rev. mvz Córdoba. 2009; 14(1): 1594-1601.

[18] Ossa GA, Suarez MA, Pérez JE. Factores ambientales y genéticos que influyen la edad al primer parto y el intervalo entre partos en hembras de la raza criolla Romosinuano. Rev. CoRpoica-Cienc. Tecnol. Agrop. 2007; 8(2): 74-80.

[19] Arellano S, Martínez J, Romero E, Briones F, Domínguez M, de la Garza F. Factores genético-ambientales que afectan el intervalo entre partos y días a primer parto en ganado de doble propósito en el norte de Veracruz. Rev. AIA. 2006; 10(1): 43-53.

[20] Vergara GO, Salgado OR, Maza AL, Botero AL, Martínez BC, Medina $\mathrm{GC}$, et al. Factores que afectan el primer intervalo de parto de hembras bovinas manejadas bajo el sistema doble propósito [en línea]. Livest. Research Rural Devel. 2007; 19(10). Disponible en http:// www.lrrd.org/lrrd19/10/verg19140.htm

[21] Pérez QGA, Gómez GMG. Factores genéticos y ambientales que afectan el comportamiento productivo de un rebaño Pardo Suizo en el trópico. 2. Intervalo entre partos y su relación con la producción de leche. Rev. Cientif. FCV-LUz. 2009; 19(1): 77-83.

[22] Salamanca CA, Quintero VR, Bentez MJ. Características de crecimiento predestete en becerros del Sistema Doble Propósito en el municipio de Arauca. Zootecnia Trop. 2011b; 29(4): 455-465.

[23] Bitew A, Taye M, Kebede A, Mekuriaw G, Tassew A, Mulugeta T, et al. Milk yield and calf growth performance of cattle under partial suckling system at Andassa Livestock Research Centre, North West Ethiopia [en línea]. Livest. Research Rural Devel. 2010; 22(8). Disponible en http://www.lrrd.org/lrrd22/8/bite22136.htm

[24] Osorio-Arce MM, Segura-Correa JC. Crecimiento pre-destete de becerros en ranchos de doble propósito en el trópico mexicano [en línea]. 
Livest. Research Rural Devel. 2008a; 20(2). Disponible en http:// www.lrrd.org/lrrd20/2/osor20018.htm

[25] Osorio-Arce MM, Segura-Correa JC. Factores que afectan el peso al nacer y al destete de becerros de doble propósito en el trópico [en línea]. Livest. Research Rural Devel. 2008b; 20(1). Disponible en http://www.lrrd.org/lrrd20/1/osor20015.htm

[26] Martínez-Tinajero JJ, Aguirre-Medina JF, Martínez-Priego G, Torres-Hernández G. Comportamiento productivo y reproductivo de tres genotipos bovinos en la región del Soconusco, Chiapas, México. Zootec. Trop. 2006; 24(2): 109-120.

[27] López-Ordaz R, Vite-Cristóbal C, García-Muñiz JG, Martínez-Hernández PA. Reproducción y producción de leche de vacas con distinta proporción de genes Bos taurus. Arch. Zootec. 2009; 58(224): 683-694.
REPORTE DE INVESTIGACIÓN

\section{ASPECTOS GENERALES DEL}

SISTEMA DE PRODUCCIÓN

GANADERA DOBLE

PROPÓSITO EN EL MUNICIPIO

DE ARAUCA [COLOMBIA]

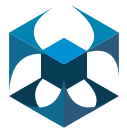


